\title{
A Novel Role for Extracellular Signal-Regulated Kinase in Maintaining Long-Term Memory-Relevant Excitability Changes
}

\author{
Sivan Ida Cohen-Matsliah, Inbar Brosh, Kobi Rosenblum, and Edi Barkai \\ Departments of Neurobiology and Biology, Faculty of Sciences, Haifa University, Haifa 39105, Israel
}

\begin{abstract}
Pyramidal neurons in the piriform cortex from olfactory-discrimination-trained rats show enhanced intrinsic neuronal excitability that lasts for several days after learning. Such enhanced intrinsic excitability is mediated by long-term reduction in the postburst afterhyperpolarization (AHP), which is generated by repetitive spike firing. AHP reduction is attributable to decreased conductance of a calciumdependent potassium current, the $s I_{\mathrm{AHP}}$. We have previously shown that such learning-induced AHP reduction is maintained by PKC activation. However, the molecular machinery underlying such long-lasting modulation of intrinsic excitability is yet to be fully described. Here we examine whether the extracellular signal-regulated kinase I/II (ERKI/II) pathway, which is known to be crucial in learning, memory, and synaptic plasticity processes, is instrumental for the long-term maintenance of learning-induced AHP reduction. PD98059 or U0126, which selectively block MEK, the upstream kinase of ERK, increased the AHP in neurons from trained rats but not in neurons from naive and pseudo-trained rats. Consequently, the differences in AHP amplitude and neuronal adaptation between neurons from trained rats and controls were abolished. This effect was not mediated by modulation of basic membrane properties. In accordance with its effect on neuronal excitability, the level of activated ERK in the membranal fraction was significantly higher in piriform cortex samples taken from trained rats. In addition, the PKC activator OAG (1-oleoyl-20acety-sn-glycerol), which was shown to reduce the AHP in neurons from control rats, had no effect on these neurons in the presence of PD98059. Our data show that ERK has a key role in maintaining long-lasting learning-induced enhancement of neuronal excitability.
\end{abstract}

Key words: olfactory learning; piriform cortex; neuronal excitability; pyramidal neurons; postburst AHP; ERK

\section{Introduction}

Learning-induced enhancement in neuronal excitability was shown after classical conditioning (Moyer et al., 1996; Thompson et al., 1996) and water-maze training (Oh et al., 2003) in hippocampal neurons and after olfactory-discrimination (OD) learning in piriform cortex neurons (for review, see Saar and Barkai, 2003). This enhanced excitability is manifested by reduced spike-frequency adaptation (Moyer et al., 1996; Saar et al., 2001) and lasts for several days after training completion (Saar and Barkai, 2003).

Neuronal adaptation is modulated by the postburst afterhyperpolarization (AHP), generated by potassium currents that develop after spike firing (Madison and Nicoll, 1984; Constanti and Sim, 1987; Schwindt et al., 1988; Saar et al., 2001). The postburst AHP is reduced after learning (Moyer et al., 1996; Saar et al., 1998). Indeed, several studies indicate that the learning-induced reduction in neuronal adaptation and in AHP amplitude results from reduction in a $\mathrm{Ca}^{2+}$-dependent potassium current

Received May 8, 2007; revised Aug. 27, 2007; accepted Aug. 27, 2007.

This work was supported by grants from the Institute for Psychobiology in Israel, the United States-Israel Binational Science Foundation, and the Israel Science Foundation.

Correspondence should be addressed to Dr. Edi Barkai, Department of Biology, Faculty of Sciences, Haifa University, Haifa 31905, Israel. E-mail: ebarkai@research.haifa.ac.il.

DOI:10.1523/JNEUROSCI.3728-07.2007

Copyright $\odot 2007$ Society for Neuroscience ～0270-6474/07/2712584-06\$15.00/0
(Sanchez-Andres and Alkon, 1991; Saar et al., 2001; Power et al., 2002). It was recently shown that only the apamin-insensitive portion of the postburst AHP is reduced after OD learning (Brosh et al., 2006), suggesting that learning modulates specifically the $s I_{\mathrm{AHP}}$. Changes in the $s I_{\mathrm{AHP}}$ were also implicated in learningrelated modifications in hippocampal neurons after spatial learning (Oh et al., 2003).

The identity of the channel that mediates the $s I_{\mathrm{AHP}}$ is yet unknown (Sah and Faber, 2002). This current is reduced by PKCdependent activation of glutamate-mediated kainite receptors (Melyan et al., 2002, 2004). Accordingly, OD learning-induced postburst AHP reduction is mediated by persistent PKC activation (Seroussi et al., 2002). The mechanism by which such longlasting PKC-dependent AHP reduction persists is yet to be described. Recently, it was shown that kainate receptor-mediated long-lasting AHP reduction in hippocampal neurons is dependent on MEK [mitogen-activated protein (MAP)/extracellular signal-regulated kinase (ERK) kinase] activation (Grabauskas et al., 2007). Thus, one possibility is that PKC maintains its activity via another signal transduction pathway such as the MAP kinase.

A wide range of studies testify to the importance for ERK in memory formation across many species and brain areas (for review, see Adams and Sweatt, 2002). In a time frame of minutes and up to a few hours, ERK activation increases transiently after acquisition of fear conditioning (Atkins et al., 1998; Schafe et al., 
2000), taste learning (Berman et al., 1998; Belelovsky et al., 2005), classical conditioning (Crow et al., 1998), and water-maze training (Blum et al., 1999).

ERK is crucially involved in both short- and long-term modulation of synaptic transmission (English and Sweatt, 1996, 1997; Atkins et al., 1998; Rosenblum et al., 2000, 2002; Thomas and Huganir, 2004). Such short-term ERK-dependent modifications may be attributable to enhancement of intrinsic neuronal excitability by modulating the $I_{\mathrm{A}}$ potassium current (Sheng et al., 1992; Yuan et al., 2002).

The purpose of the present study was to examine the involvement of ERK in maintenance of long-lasting olfactory learninginduced enhancement of neuronal excitability and to test whether such long-term modulation is related to the effect of PKC on the postburst AHP.

\section{Materials and Methods \\ Animal training}

Subjects and apparatus. Age-matched young adult Sprague Dawley male rats were used. Before training, they were maintained on a $23.5 \mathrm{~h}$ waterdeprivation schedule, with food available ad libitum. The OD training protocol was performed daily on each trained and pseudo-trained rat in a four-arm radial maze, as described previously (Saar et al., 1999, 2001), with commercial odors that are regularly used in the cosmetics and food industries.

Training. Olfactory training consisted of 20 trials per day for each rat as described previously (Saar et al., 2001). In short, in each trial the rat had to choose between two odors (positive and negative cues) presented simultaneously. Rats designated to the trained group were rewarded after choosing the positive cue. Rats in the pseudo-trained group were rewarded in a random manner, after choosing any odor. The criterion for learning was at least $80 \%$ positive-cue choices in the last 10 trials of a training day, as was used previously (Staubli et al., 1987; Saar et al., 1999, 2001). Rats in the naive group were water restricted but not exposed to the maze. Typically, two to three trained rats and two to three pseudotrained rats were trained at the same training period, and all the rats in the trained group had to meet the criteria for the first pair of odors before all trained and pseudo-trained rats were exposed to a second pair of odors. Training for a new pair began only after training for the second pair was completed for all rats. Rats were trained to discriminate between three pairs of odors, to confirm that rule learning was achieved and to ensure that rats are always killed $3 \mathrm{~d}$ after the last training session. As described previously (Saar et al., 1999, 2001), rats indeed learned the second and third pairs of odors much faster than the first pair (7-8 $\mathrm{d}$ of training for the first pair and $1-2 \mathrm{~d}$ for the second and third pairs). A detailed description of OD learning efficacy was described previously (Zelcer et al., 2006).

\section{Slice preparation, stimulation, and recording}

Coronal brain slices $(400 \mu \mathrm{m})$ were cut as described previously (Saar et al., 1998) and kept in oxygenated $\left(95 \% \mathrm{O}_{2}\right.$ plus $\left.5 \% \mathrm{CO}_{2}\right)$ normal saline Ringer's (NSR) solution (in mM: $124 \mathrm{NaCl}, 3 \mathrm{KCl}, 2 \mathrm{MgSO}_{4}, 1.25$ $\mathrm{NaH}_{2} \mathrm{PO}_{4}, 26 \mathrm{NaHCO}_{3}, 2 \mathrm{CaCl}_{2}$, and 10 glucose). Intracellular recordings were obtained from pyramidal cells in layer II of the piriform cortex, with $4 \mathrm{M} \mathrm{K}$-acetate-filled sharp glass microelectrodes, at $35^{\circ} \mathrm{C}$. Several piriform cortex slices were obtained from each rat.

AHPs were recorded within minutes after good recording conditions were established (resting potential of at least $-65 \mathrm{mV}$ and action potential amplitude of $\geq 80 \mathrm{mV}$ ). To standardize AHP recordings, neurons were depolarized to a holding potential of $-60 \mathrm{mV}$ by direct current application via the recording electrode. Postburst AHP amplitude was then measured after a $100 \mathrm{~ms}$ depolarizing current step with intensity that generates six action potentials. The AHP amplitude was determined from an average of eight consecutive measurements of AHP evoked in responses to stimuli applied once every $10 \mathrm{~s}$.

The postburst AHP amplitude was measured from baseline to the peak of the hyperpolarizing voltage deflection that follows an evoked train of six action potentials (see Fig. 1). The stimulus intensity required to evoke six action potentials always remained constant throughout the recording period of each neuron, before and after drug application. Such stability of the required stimulus intensity well coincides with the stability of basic membrane properties, such as the input resistance or resting potential of the neurons, which are not affected by the drugs [see Results and also Seroussi et al. (2002)].

The identity of the rat from which neurons were recorded (naive, trained, or pseudo-trained) was not known to the person conducting the experiments and measurements.

All drugs were applied into the perfusing Ringer's solution, at the following concentrations: MEK inhibitor PD98059, $38 \mu \mathrm{M}$; MEK inhibitor UO126, $30 \mu \mathrm{M}$; 1-oleoyl-20acety-sn-glycerol (OAG), $10 \mu \mathrm{M}$. Slices were exposed to drugs for at least $20 \mathrm{~min}$ before the recordings. In NSR solution and PD98059, several cells were recorded before and after drug application, whereas others were recorded under one condition only. All cells in OAG and UO126 were recorded before and after drug application.

\section{Sample preparation}

Preparation of membranal fraction. The protocol was adapted from Schilstrom et al. (2006). Piriform cortices from both hemispheres of each rat were homogenized in a Teflon/glass $1 \mathrm{ml}$ tissue grinder and with $800 \mu \mathrm{l}$ of homogenization buffer [10 mm Tris-HCl, pH 7.4, 2 mm EDTA, 2 mM EGTA, $0.5 \mathrm{~mm}$ DTT, $100 \mathrm{~mm} \mathrm{Na}_{3} \mathrm{VO}_{4}, 5 \mathrm{~mm} \mathrm{NaF}, 10 \mu \mathrm{g} / \mathrm{ml}$ aprotinin, $10 \mu \mathrm{g} / \mathrm{ml}$ leupeptin, $0.32 \mathrm{M}$ sucrose, $100 \mathrm{~mm}$ PMSF, $1 \%$ phosphatase inhibitor mixture (Sigma, St. Louis, MO), and 1\% protease inhibitor mixture (Sigma)]. Samples were sonicated and kept on ice for $30 \mathrm{~min}$. An aliquot of the homogenized tissue $(80 \mu \mathrm{l})$ was retained and mixed with $80 \mu \mathrm{l}$ of SDS sample buffer (total fraction). The remaining material was centrifuged at $1000 \times g$ for 3 $\min$. The supernatant was centrifuged at $20,000 \times g$ for $1 \mathrm{~h}$. The pellet, containing the crude synatposomal membranes (membranal fraction), was resuspended in lysis buffer [10 mM Tris- $\mathrm{HCl}, \mathrm{pH}$ 7.4, 2 mM EDTA, $2 \mathrm{~mm}$ EGTA, $0.5 \mathrm{~mm}$ DTT, $100 \mathrm{~mm} \mathrm{Na} \mathrm{VO}_{4}, 5 \mathrm{~mm} \mathrm{NaF}, 10 \mu \mathrm{g} / \mathrm{ml}$ aprotinin, 10 $\mu \mathrm{g} / \mathrm{ml}$ leupeptin, $1 \%$ Triton, $1 \%$ phosphatase inhibitor mixture (Sigma), and $1 \%$ protease inhibitor mixture (Sigma)], whereas the cytosol and light membranes remained in the supernatant (cytosol fraction). SDS sample buffer was added to both the pellet and supernatant fractions. Samples were stored at $-80^{\circ} \mathrm{C}$ until further use.

\section{Western blot analysis}

All samples were resolved by SDS-PAGE and transferred to nitrocellulose membrane (Bio-Rad, Hercules, CA) for immunoblotting. Blots were visualized with enhanced chemiluminescence (ECL Plus; Amersham Biosciences, Piscataway, NJ) and quantified using a CCD camera (XRS; Bio-Rad) and Quantity-One software. The ratio between phosphorylated ERK (pERK) and the total amount of the protein for each rat was calculated and normalized to the naive group average run on the same gel.

The following reagents were used: p44/42 MAP kinase antibody (rabbit polyclonal, 1:1000; Cell Signaling Technology, Beverly, MA), phospho-p44/42 MAP kinase (Thr202/Tyr204) antibody (1:500; Cell Signaling Technology), and goat anti-rabbit $\operatorname{IgG}(1: 20,000 ;$ Jackson ImmunoResearch, West Grove, PA).

\section{Statistical analysis}

For all the electrophysiological measurements, between-groups comparison was done using one-way ANOVA for the three groups (naive, trained, and pseudo-trained), and post hoc multiple $t$ tests were than applied to compare between each two groups. The effect of PD98059, UO126, and OAG on each of the three groups was evaluated by comparing the recordings from the same group, with and without the treatment, using independent $t$ tests. Values throughout the text are presented as mean $\pm \mathrm{SD}$. Data in graphs are presented as mean $\pm \mathrm{SE}$.

\section{Results}

Recordings in neurons from trained and pseudo-trained rats were performed $3 \mathrm{~d}$ after the last training session, when learning-related reduction in AHP amplitude is most prominent (Saar and Barkai, 2003). In control saline Ringer's solution (NSR solution), the averaged postburst AHP in neurons from trained rats was significantly smaller compared with the averaged AHP amplitudes in neurons 
from pseudo-trained and naive rats (Fig. 1C) (see also details below), confirming our previous reports (Saar et al., 1998, 2001; Brosh et al., 2006). As reported previously (Saar et al., 1998, 2001), resting membrane potential (naive: $-79.3 \pm 7.3 \mathrm{mV}, n=34$; trained: $-79.2 \pm 7.0 \mathrm{mV}, n=49$; pseudotrained: $-82.0 \pm 7.4 \mathrm{mV}, n=34)$ and input resistance (naive: $33.4 \pm 12.7 \mathrm{M} \Omega, n=24$; trained: $30.0 \pm 8.4 \mathrm{M} \Omega, n=30$; pseudotrained: $35.8 \pm 10.9 \mathrm{M} \Omega, n=18$ ) did not differ between neurons from the three groups.

\section{Learning-induced long-lasting AHP reduction is abolished by \\ ERK inhibition}

To examine whether the long-lasting reduction in postburst AHP amplitude is maintained by ERK activation, we applied the MEK inhibitors PD98059 (38 $\mu \mathrm{M})$ and UO126 (30 $\mu \mathrm{M})$. PD98059 significantly increased the AHP amplitude in neurons from trained rats only. In neurons from naive and pseudo-trained rats, the averaged AHP value was not affected by the inhibitor. In neurons from trained rats, the averaged AHP value was significantly increased from $5.57 \pm 1.80(n=48)$ in NSR solution to $6.89 \pm 2.51(n=12)$ in PD98059 $(p<0.05)$. For naive rats, the averaged values were $7.04 \pm 1.89(n=21)$ in NSR solution and $6.34 \pm 1.20(n=11)$ in PD98059. For pseudo-trained rats, the averaged values were $7.94 \pm 1.72(n=26)$ in NSR solution and $7.18 \pm 1.89(n=13)$ in PD98059. Two typical examples for the different effect of PD98059 on neurons from a pseudo-trained and a trained rat are shown in Figure $1, A$ and $B$. After PD98059 application, the difference in AHP amplitude between neurons from trained rats and controls was abolished (Fig. 1C). Similar results were obtained with the second specific MEK inhibitor, UO126. In neurons from trained rats, the averaged AHP value was significantly increased to $7.56 \pm 1.38(n=7 ; p<0.05)$. In neurons from naive rats, the averaged value in UO126 was to $7.81 \pm 1.11(n=5)$, and in neurons from pseudo-trained rats, the averaged value in UO126 was $7.15 \pm$ $1.48(n=7)$. These values were not different from the averaged values recorded in NSR solution (Fig. 1C).

\section{MEK inhibitors reduce neuronal excitability in neurons from trained rats only}

A direct consequence of the learning-induced AHP reduction is enhanced neuronal excitability. Such enhancement is manifested by increased frequency of repetitive firing in response to a prolonged depolarizing pulse applied via the recording electrode (Saar et al., 2001; Saar and Barkai, 2003). To examine whether ERK activation underlies the maintenance of such learninginduced neuronal excitability, we compared the effect of its in-
B

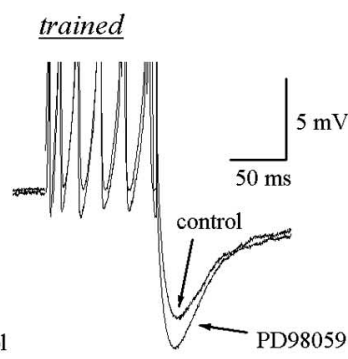

$\mathrm{C}$

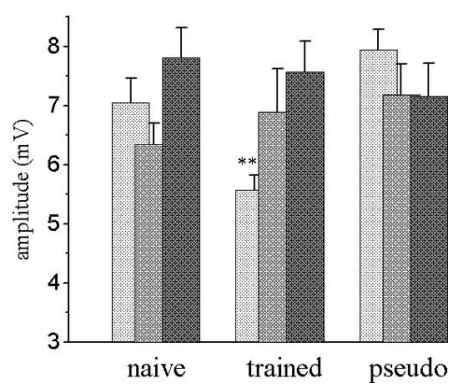

Figure 1. MEK inhibitors increase the AHP in neurons from trained rats only. AHP measurements in piriform cortex neurons are shown. Neurons were held at a membrane potential of $-60 \mathrm{mV}$, and the postburst AHP was generated by a $100 \mathrm{~ms}$ depolarizing current step injection via the recording electrode, with intensity sufficient to generate a train of six action potentials. $\boldsymbol{A}, \boldsymbol{B}$, hough PD98059 application had no effect on a neuron from a pseudo-trained rat $(\boldsymbol{A})$, it enhanced the AHP in a neuron from a Averaged AHP amplitude in trained rats is significantly smaller compared with naive and pseudo-trained rats $\left({ }^{* *} p<\right.$ 作 and six pseudo-trained rats. AHP in PD98059 was measured in neurons from four naive rats, five trained rats, and five pseudotrained rats. Values represent mean $\pm \mathrm{SE}$.

A control

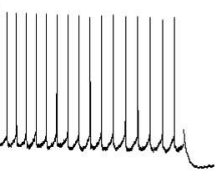

pseudo

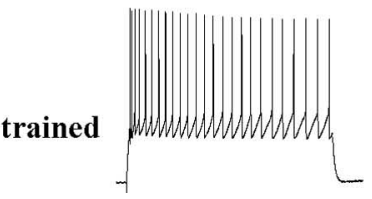

$\underline{P D 98509}$
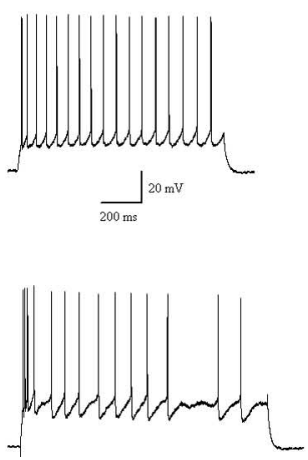

B

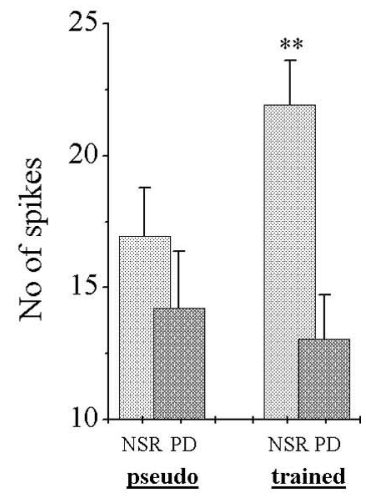

Figure 2. PD98059 reduced neuronal excitability in neurons from trained rats. $\boldsymbol{A}$, Examples for the effect of PD98059 on repetitive spike firing in a neuron from a pseudo-trained rat and a neuron from a trained rat. With a stimulus intensity of $I_{\text {th }} \times 2$, $1 \mathrm{~s}$ depolarizing pulse generates repetitive firing throughout the stimulation period. Although PD98059 has no effect on the P) application has no effect on the number of spikes evoked in neurons from pseudo-trained rats, it significantly reduces the neurons from five pseudo-trained and seven trained rats. Stimulus intensity was kept constant in each cell throughout the recording period. Values represent mean $\pm \mathrm{SE}$.

hibitor on the number of spikes generated by a $1 \mathrm{~s}$ depolarizing pulse, with a stimulus intensity of $I_{\text {th }} \times 2$.

As described previously (Saar et al., 2001), the averaged number of action potentials evoked in neurons from trained rats in NSR solution $(21.9 \pm 9.1 ; n=30)$ was significantly $(p<0.05)$ higher compared with neurons from pseudo-trained rats $(16.9 \pm$ $7.7 ; n=17)$. As shown in Figure 2, application of PD98059 significantly reduced $(p<0.01)$ the averaged number of spikes in neurons from trained rats $(13.1 \pm 7.0 ; n=18)$ but had no effect on the averaged value in neurons from pseudo-trained rats $(14.2 \pm 7.7 ; n=13)$. Similar results were obtained with UO126. In neurons from trained rats, the averaged number of spikes reduced to $17.0(n=6)$. In neurons from naive rats, the averaged value in UO126 was $17.4(n=5)$, and in neurons from pseudo- 
A

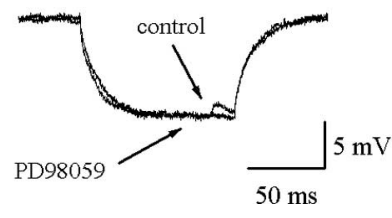

B

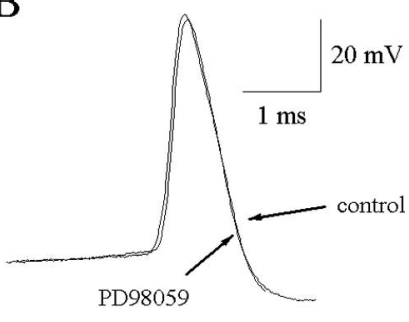

Figure 3. PD98059 does not affect basic membrane properties. A, An example of the lack of effect of PD98059 on resting membrane potential and input resistance in a neuron from a pseudo-trained rat. The resting potential was $-80 \mathrm{mV}$; input resistance is measured by the voltage deflection in response to a 100 pulse of $-0.3 \mathrm{nA}$, applied via the recording electrode. $\boldsymbol{B}$, An example of lack of effect of PD98059 on the duration of the action potential in a neuron from a trained rat.

trained rats, the averaged value was $18.2(n=8)$. Thus, the difference in repetitive spike firing was also abolished by UO126.

\section{The effects of MEK inhibition on neurons from trained rats are not the result of changes in basic neuronal properties} Such learning-induced modification of ERK inhibition on the postburst AHP may be the result of a direct effect on the currents underlying the postburst AHP, by modulating the properties of single action potentials via inhibition of the $I_{\mathrm{A}}$ potassium current (Yuan et al., 2002), or by a nonspecific effect on basic membrane properties. For example, a learning-induced increase in the averaged input resistance or the averaged width of single action potentials of neurons would result in enhanced postburst AHP without modifying its underlying currents directly. Our data show that such a nonspecific effect was not induced by PD98059 application.

Resting membrane potential in neurons from the three groups (naive: $-79.5 \pm 6.1 \mathrm{mV}, n=19$; trained: $-80.1 \pm 7.5 \mathrm{mV}, n=$ 14; pseudo-trained: $-81.3 \pm 6.5 \mathrm{mV}, n=15$ ) and input resistance (naive: $36.7 \pm 12.6 \mathrm{M} \Omega, n=16$; trained: $30.7 \pm 11.9 \mathrm{M} \Omega$, $n=13$; pseudo-trained: $35.5 \pm 10.6 \mathrm{M} \Omega, n=13$ ) were not affected by PD98059 application.

As reported previously (Saar et al., 1998; Brosh et al., 2006), the averaged action potential duration in NSR solution was similar in all groups (naive: $1.44 \pm 0.24 \mathrm{~ms}, n=34$; trained: $1.51 \pm$ $0.30, n=49$; pseudo-trained: $1.44 \pm 0.20, n=34)$. These values were not modified by PD98059 application (naive: $1.59 \pm 0.37$ ms, $n=19$; trained: $1.54 \pm 0.29, n=14$; pseudo-trained: $1.35 \pm$ $0.24, n=15$ ) (Fig. 3).

\section{OD learning induces long-term membranal ERK activation}

Because learning-induced enhancement of neuronal excitability and the postburst AHP reduction are dependent of persistent ERK activation, we hypothesized that learning should be accompanied by an increased ERK phosphorylation. Using Western blot analysis, we measured the total amount of ERK and its phosphorylation state in the three experimental groups. We found that although the basal ERK protein level in the membranal fraction was not modified, the level of pERK significantly increased after learning (Fig. 4). Such increase in ERK phosphorylation was specific to the membranal fraction; no differences were observed between groups for the total homogenate fraction (total amount of ERK: naive, $1.00 \pm 0.06$; pseudo-trained, $1.02 \pm 0.07$; trained, $1.01 \pm 0.07$; pERK/ERK ratio: naive, $1.03 \pm 0.09$; pseudotrained, $0.91 \pm 0.1$; trained, $1.04 \pm 0.09$ ) nor for the cytosolic fraction (total amount of ERK: naive, $1.00 \pm 0.05$; pseudo-

A

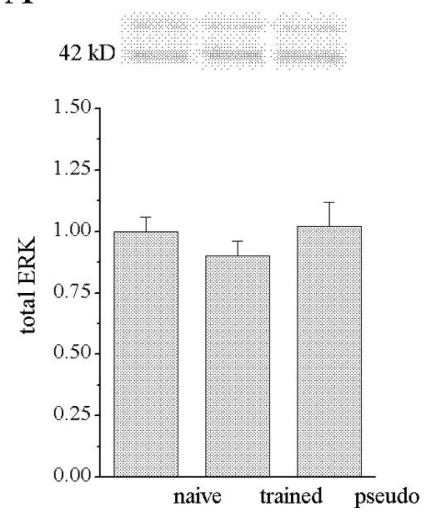

B

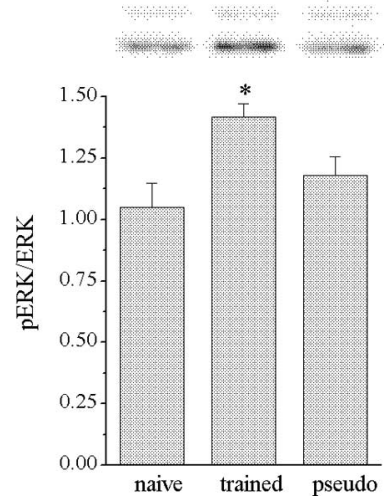

Figure 4. Membranal ERK is activated $3 \mathrm{~d}$ after learning. $\boldsymbol{A}$, Protein expression level of ERKII is not modified after olfactory learning. The protein level is normalized to the average value obtained from the naive animals. Summarized data are presented as mean $0 D \pm S E ; n=9$ rats for each experimental group. Above are representative immunoblots for ERKI/II protein prepared from the piriform cortex of naive, pseudo-trained, and trained animals. $\boldsymbol{B}$, After learning the level of $p E R K I I$ is increased. Summarized data are presented as the ratio of $p$ ERKII/total ERKII; $n=9$ rats for each experimental group. Above are representative immunoblots for pERKII prepared from piriform cortex of each of the three groups. Values represent mean $\pm \mathrm{SE}$.

trained, $1.01 \pm 0.06$; trained, $1.05 \pm 0.06$; pERK/ERK ratio: naive, $1.00 \pm 0.05$; pseudo-trained, $1.00 \pm 0.08$; trained, $1.08 \pm$ 0.08 ). (For all the measurements, $n=9$ rats in each group.)

These results also suggest that ERK activation is both correlated and necessary for the maintenance of learning-relevant enhancement in neuronal excitability.

\section{PKC-induced AHP reduction is ERK dependent}

Recordings performed in piriform cortex neurons after olfactory learning show that the PKC blocker GF-109203X increases the AHP in neurons from trained rats only, and that the PKC activator $\mathrm{OAG}$ reduced the AHP in neurons from control groups more than in neurons from trained rats (Seroussi et al., 2002). In particular, the PKC activator reduced the AHP in neurons from naive rats by $40 \%$ (Seroussi et al., 2002). We hypothesized that if PKC-induced reduction of the AHP is mediated via ERK activation, application of PD98059 should block its effect. As shown previously (Seroussi et al., 2002), the PKC activator OAG (10 $\mu \mathrm{M})$ significantly reduces the postburst AHP in neurons from naive rats (from $7.2 \pm 2.4$ in control conditions to $5.1 \pm 0.54$ after OAG application; $n=6$ ). An example of OAG effect on such a naive neuron is shown in Figure $5 A$. In sharp contrast, in the presence of the MEK inhibitor, the PKC activator did not have a significant effect of the averaged AHP amplitude in neurons from naive rats $[6.20 \pm 2.35(n=8)$ in PD98059 compared with $5.46 \pm 1.36$ in the same eight neurons after OAG application], and accordingly, it also did not affect the repetitive spike firing (Fig. 5).

\section{Discussion}

Previous studies have shown that olfactory learning-induced long-lasting enhancement of neuronal excitability is the result of reduction in the conductance of the acetylcholine-sensitive, calcium-dependent current, the $s I_{\mathrm{AHP}}$ (Saar et al., 2001; Saar and Barkai, 2003; Brosh et al., 2006). Here we show that ERK activation is both correlated and necessary for such long-term enhanced excitability.

\section{ERK activation modifies neuronal excitability only after learning}

Our data show that in piriform cortex layer II pyramidal neurons, the postburst AHP amplitude as well as neuronal adaptation are 
subjected to modifications by ERK only after learning, when both the AHP amplitude and neuronal adaptation are reduced. The block of ERK activity results with complete abolishment of the learning-induced modifications in intrinsic neuronal properties. This robust effect suggests that persistent ERK activation is an obligatory condition for maintaining the neuron in its highly excitable state. Interestingly, before OD learning, ERK has no significant effect on the postburst AHP in piriform cortex neurons, although ERK is activated to a considerable level in control conditions ( $p E R K / E R K$ ratio of $\sim 1$ in brains of control rats). This finding suggests that ERK activation is necessary but not sufficient for persistent AHP reduction.

We also show that such modifications in intrinsic neuronal excitability, which last for $3 \mathrm{~d}$ after rule learning, are mediated by membrane-specific, long-term ERK activation. The activity level of ERK in the total and cytosolic fractions, which is known to mediate many cellular events, is similar in all groups. This sitespecific ERK activation, next to the cell membrane, supports the notion of its possible modulation of a channel(s) that mediates the ionic currents that underlie the learning-induced modifications.

\section{ERK affects neuronal excitability by direct modulation of the postburst AHP}

Increased neuronal excitability is frequently the result of phosphorylation-dependent modulation of ionic channels. The postburst AHP is affected by activation of PKC (Malenka et al., 1986; Agopyan and Agopyan, 1991; Pineda et al., 1995; Seroussi et al., 2002), protein kinase A (PKA) (Pedarzani and Storm, 1993; Pedarzani et al., 1998; Haug and Storm, 2000; Seroussi et al., 2002), and $\mathrm{Ca}^{2+}$-calmodulin kinase II (Sah, 1996).

Although the effects of ERK on the postburst AHP and neuronal adaptation after learning imply that its primary role after learning is to maintain the reduced conductance of the $s I_{\mathrm{AHP}}$, other potential effects on basic membranal properties such as input resistance or the duration of the single action potential would also be manifested by modulating repetitive firing and amplitude of calcium-dependent potassium currents. In particular, ERK phosphorylation was shown to affect the A-type potassium current $\left(I_{\mathrm{A}}\right)$ (Adams et al., 2000; Hu et al., 2003). The $I_{\mathrm{A}}$ current is primarily localized in the somas and dendrites (Sheng et al., 1992; Maletic-Savatic et al., 1995) and strongly affects the action poential duration (Kim and Chang, 2005).

Our data indicate that the basic membrane properties, such as resting potential, input resistance, and action potential width and amplitude, are not affected by ERK inhibition. Thus, we suggest that phosphorylation of the $I_{\mathrm{A}}$ channels by ERK is probably not the mechanism underling the learning-induced modifications in the postburst AHP, at least at the time point we examined $(3 \mathrm{~d}$ after rule-learning acquisition).

\section{ERK activation is required for PKC-induced modulation of neuronal excitability}

We have previously shown that the maintenance of the olfactory learning-induced reduction of the AHP is dependent on PKC but not PKA activation (Seroussi et al., 2002). Here we show that the involvement of PKC in maintenance of the learning-induced neuronal excitability is mediated via ERK activation. The selec-
B
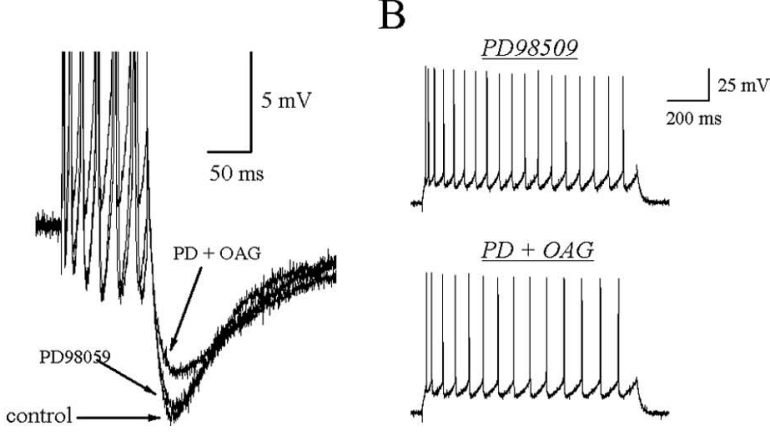
Figure 5. PKC activation does not reduce the AHP amplitude in the presence of the ERK inhibitor. A, An example of the effect of
the PKC activator OAG on a neuron taken from a naive rat in control conditions (left trace) and the lack of such effect on another neuron from a naive rat in the presence of PD98059 (PD; right trace). B, According to its lack of effect on the AHP, OAG does not enhance the firing rate of a naive neuron in the presence of $\mathrm{PD}$.

tive MEK inhibitor PD98059 was shown to inhibit up to $90 \%$ of ERK activation (Alessi et al., 1995), without affecting PKC activity (Blum et al., 1999). Here application of PD98059 to slices from control rats abolishes the typical reduction in AHP amplitude observed in these neurons when the PKC agonist OAG is applied. Thus, we suggest that the effect of PKC on learning-induced neuronal excitability is mediated by ERK activation. A similar sequence of events was suggested to describe the effect of PKC on the $I_{\mathrm{A}}$ potassium current (Hu et al., 2003).

\section{Time-specific effects of ERK on learning and memory}

Direct evidence in support of a role for ERK in memory has been accumulating rapidly over the past decade. Although the evidences stem from findings involving different learning types and brain areas, they all show a pattern of temporal ERK activation, initiated minutes to several hours after training completion (Atkins et al., 1998; Berman et al., 1998; Blum et al., 1999; Schafe et al., 2000; Belelovsky et al., 2005; Herry et al., 2006). The picture emerging from these previous studies is that at relatively early stages of memory formation and maintenance, ERKs modulate learning-relevant processes by affecting different substrates, which are yet to be identified.

Our study shows that at a later stage, days after learning completion, ERK is still activated at a specific cellular compartment and that such activation is necessary for maintaining learninginduced cellular modifications. However, at this time point its action is aimed directly or indirectly at a new target, the slow calcium-dependent potassium current.

In conclusion, our study shows that ERK activation is crucial for maintaining learning-induced cellular modifications for days after learning completion while having no effect on basal levels of cellular properties. Such activation is crucial for persistent reduction of the $s I_{\mathrm{AHP}}$, which results with long-lasting enhancement of neuronal excitability. This enhanced excitability plays a key role in maintaining the cortical network in a "learning mode" in which memories can be stored rapidly and efficiently (Barkai and Hasselmo, 1994; Saar and Barkai, 2003).

\section{References}

Adams JP, Sweatt JD (2002) Molecular psychology: roles for the ERK MAP kinase cascade in memory. Annu Rev Pharmacol Toxicol 42:135-163.

Adams JP, Anderson AE, Varga AW, Dineley KT, Cook RG, Pfaffinger PJ, Sweatt JD (2000) The A-type potassium channel Kv4.2 is a substrate for the mitogen-activated protein kinase ERK. J Neurochem 75:2277-2287.

Agopyan N, Agopyan I (1991) Effects of protein kinase C activators and inhibitors on membrane properties, synaptic responses, and cholinergic 
actions in CA1 subfield of rat hippocampus in situ and in vitro. Synapse 7:193-206.

Alessi DR, Cuenda A, Cohen P, Dudley DT, Saltiel AR (1995) PD 098059 is a specific inhibitor of the activation of mitogen-activated protein kinase kinase in vitro and in vivo. J Biol Chem 270:27489-27494.

Atkins CM, Selcher JC, Petraitis JJ, Trzaskos JM, Sweatt JD (1998) The MAPK cascade is required for mammalian associative learning. Nat Neurosci 1:602-609.

Barkai E, Hasselmo ME (1994) Modulation of the input/output function of rat piriform cortex pyramidal cells. J Neurophysiol 72:644-658.

Belelovsky K, Elkobi A, Kaphzan H, Nairn AC, Rosenblum K (2005) A molecular switch for translational control in taste memory consolidation. Eur J Neurosci 22:2560-2568.

Berman DE, Hazvi S, Rosenblum K, Seger R, Dudai Y (1998) Specific and differential activation of mitogen-activated protein kinase cascades by unfamiliar taste in the insular cortex of the behaving rat. J Neurosci 18:10037-10044.

Blum S, Moore AN, Adams F, Dash PK (1999) A mitogen-activated protein kinase cascade in the CA1/CA2 subfield of the dorsal hippocampus is essential for long-term spatial memory. J Neurosci 19:3535-3544.

Brosh I, Rosenblum K, Barkai E (2006) Learning-induced reversal of the effect of noradrenalin on the postburst AHP. J Neurophysiol 96:1728-1733.

Constanti A, Sim JA (1987) Calcium-dependent potassium conductance in guinea-pig olfactory cortex neurones in vitro. J Physiol (Lond) 387:173-194.

Crow T, Xue-Bian JJ, Siddiqi V, Kang Y, Neary JT (1998) Phosphorylation of mitogen-activated protein kinase by one-trial and multi-trial classical conditioning. J Neurosci 18:3480-3487.

English JD, Sweatt JD (1996) Activation of p42 mitogen-activated protein kinase in hippocampal long term potentiation. J Biol Chem 271:24329-24332.

English JD, Sweatt JD (1997) A requirement for the mitogen-activated protein kinase cascade in hippocampal long term potentiation. J Biol Chem 272:19103-19106.

Grabauskas G, Lancaster B, O'connor V, Wheal HV (2007) Protein kinase signalling requirements for metabotropic action of kainate receptors in rat CA1 pyramidal neurones. J Physiol (Lond) 579 2:363-373.

Haug T, Storm JF (2000) Protein kinase A mediates the modulation of the slow $\mathrm{Ca}(2+)$-dependent $\mathrm{K}(+)$ current, $\mathrm{I}($ sAHP $)$, by the neuropeptides CRF, VIP, and CGRP in hippocampal pyramidal neurons. J Neurophysiol 83:2071-2079.

Herry C, Trifilieff P, Micheau J, Luthi A, Mons N (2006) Extinction of auditory fear conditioning requires MAPK/ERK activation in the basolateral amygdala. Eur J Neurosci 24:261-269.

Hu HJ, Glauner KS, Gereau RW (2003) ERK integrates PKA and PKC signaling in superficial dorsal horn neurons. I. Modulation of A-type K+ currents. J Neurophysiol 90:1671-1679.

Kim U, Chang SY (2005) Dendritic morphology, local circuitry, and intrinsic electrophysiology of neurons in the rat medial and lateral habenular nuclei of the epithalamus. J Comp Neurol 483:236-250.

Madison DV, Nicoll RA (1984) Control of the repetitive discharge of rat CA1 pyramidal neurones in vitro. J Physiol (Lond) 354:319-331.

Malenka RC, Madison DV, Andrade R, Nicoll RA (1986) Phorbol esters mimic some cholinergic actions in hippocampal pyramidal neurons. J Neurosci 6:475-480.

Maletic-Savatic M, Lenn NJ, Trimmer JS (1995) Differential spatiotemporal expression of $\mathrm{K}^{+}$channel polypeptides in rat hippocampal neurons developing in situ and in vitro. J Neurosci 15:3840-3851.

Melyan Z, Wheal HV, Lancaster B (2002) Metabotropic-mediated kainate receptor regulation of IsAHP and excitability in pyramidal cells. Neuron 34:107-114.

Melyan Z, Lancaster B, Wheal HV (2004) Metabotropic regulation of intrinsic excitability by synaptic activation of kainate receptors. J Neurosci 24:4530-4534.

Moyer Jr JR, Thompson LT, Disterhoft JF (1996) Trace eyeblink conditioning increases CA1 excitability in a transient and learning-specific manner. J Neurosci 16:5536-5546.
Oh MM, Kuo AG, Wu WW, Sametsky EA, Disterhoft JF (2003) Watermaze learning enhances excitability of CA1 pyramidal neurons. J Neurophysiol 90:2171-2179.

Pedarzani P, Storm JF (1993) PKA mediates the effects of monoamine transmitters on the $\mathrm{K}+$ current underlying the slow spike frequency adaptation in hippocampal neurons. Neuron 11:1023-1035.

Pedarzani P, Krause M, Haug T, Storm JF, Stuhmer W (1998) Modulation of the $\mathrm{Ca} 2+$-activated $\mathrm{K}+$ current sIAHP by a phosphatase-kinase balance under basal conditions in rat CA1 pyramidal neurons. J Neurophysiol 79:3252-3256.

Pineda JC, Bargas J, Flores-Hernandez J, Galarraga E (1995) Muscarinic receptors modulate the afterhyperpolarizing potential in neostriatal neurons. Eur J Pharmacol 281:271-277.

Power JM, Wu WW, Sametsky E, Oh MM, Disterhoft JF (2002) Age-related enhancement of the slow outward calcium-activated potassium current in hippocampal CA1 pyramidal neurons in vitro. J Neurosci 22:7234-7243.

Rosenblum K, Futter M, Jones M, Hulme EC, Bliss TV (2000) ERKI/II regulation by the muscarinic acetylcholine receptors in neurons. J Neurosci 20:977-985.

Rosenblum K, Futter M, Voss K, Erent M, Skehel PA, French P, Obosi L, Jones MW, Bliss TV (2002) The role of extracellular regulated kinases I/II in late-phase long-term potentiation. J Neurosci 22:5432-5441.

Saar D, Barkai E (2003) Long-term modifications in intrinsic neuronal properties and rule learning in rats. Eur J Neurosci 17:2727-2734.

Saar D, Grossman Y, Barkai E (1998) Reduced after-hyperpolarization in rat piriform cortex pyramidal neurons is associated with increased learning capability during operant conditioning. Eur J Neurosci 10:1518-1523.

Saar D, Grossman Y, Barkai E (1999) Reduced synaptic facilitation between pyramidal neurons in the piriform cortex after odor learning. J Neurosci 19:8616-8622.

Saar D, Grossman Y, Barkai E (2001) Long-lasting cholinergic modulation underlies rule learning in rats. J Neurosci 21:1385-1392.

Sah P (1996) Ca(2+)-activated K+ currents in neurones: types, physiological roles and modulation. Trends Neurosci 19:150-154.

Sah P, Faber ES (2002) Channels underlying neuronal calcium-activated potassium currents. Prog Neurobiol 66:345-353.

Sanchez-Andres JV, Alkon DL (1991) Voltage-clamp analysis of the effects of classical conditioning on the hippocampus. J Neurophysiol 65:796-807.

Schafe GE, Atkins CM, Swank MW, Bauer EP, Sweatt JD, LeDoux JE (2000) Activation of ERK/MAP kinase in the amygdala is required for memory consolidation of pavlovian fear conditioning. J Neurosci 20:8177-8187.

Schilstrom B, Yaka R, Argilli E, Suvarna N, Schumann J, Chen BT, Carman M, Singh V, Mailliard WS, Ron D, Bonci A (2006) Cocaine enhances NMDA receptor-mediated currents in ventral tegmental area cells via dopamine $\mathrm{D}_{5}$ receptor-dependent redistribution of NMDA receptors. J Neurosci 26:8549-8558.

Schwindt PC, Spain WJ, Foehring RC, Chubb MC, Crill WE (1988) Slow conductances in neurons from cat sensorimotor cortex in vitro and their role in slow excitability changes. J Neurophysiol 59:450-467.

Seroussi Y, Brosh I, Barkai E (2002) Learning-induced reduction in postburst after-hyperpolarization (AHP) is mediated by activation of PKC. Eur J Neurosci 16:965-969.

Sheng M, Tsaur ML, Jan YN, Jan LY (1992) Subcellular segregation of two A-type $\mathrm{K}+$ channel proteins in rat central neurons. Neuron 9:271-284.

Staubli U, Fraser D, Faraday R, Lynch G (1987) Olfaction and the "data" memory system in rats. Behav Neurosci 101:757-765.

Thomas GM, Huganir RL (2004) MAPK cascade signalling and synaptic plasticity. Nat Rev Neurosci 5:173-183.

Thompson LT, Moyer Jr JR, Disterhoft JF (1996) Transient changes in excitability of rabbit CA3 neurons with a time course appropriate to support memory consolidation. J Neurophysiol 76:1836-1849.

Yuan LL, Adams JP, Swank M, Sweatt JD, Johnston D (2002) Protein kinase modulation of dendritic $\mathrm{K}^{+}$channels in hippocampus involves a mitogen-activated protein kinase pathway. J Neurosci 22:4860-4868.

Zelcer I, Cohen H, Richter-Levin G, Lebiosn T, Grossberger T, Barkai E (2006) A cellular correlate of Learning-induced metaplasticity in the hippocampus. Cereb Cortex 16:460-468. 